\title{
Molecular signatures that correlate with induction of lens regeneration in newts: lessons from proteomic analysis
}

\author{
Konstantinos Sousounis ${ }^{1}$, Rital Bhavsar ${ }^{1}$, Mario Looso², Marcus Krüger², Jessica Beebe ${ }^{1}$, Thomas Braun² \\ and Panagiotis A Tsonis ${ }^{1 *}$
}

\begin{abstract}
Background: Amphibians have the remarkable ability to regenerate missing body parts. After complete removal of the eye lens, the dorsal but not the ventral iris will transdifferentiate to regenerate an exact replica of the lost lens. We used reverse-phase nano-liquid chromatography followed by mass spectrometry to detect protein concentrations in dorsal and ventral iris 0,4 , and 8 days post-lentectomy. We performed gene expression comparisons between regeneration and intact timepoints as well as between dorsal and ventral iris.

Results: Our analysis revealed gene expression patterns associated with the ability of the dorsal iris for transdifferentiation and lens regeneration. Proteins regulating gene expression and various metabolic processes were enriched in regeneration timepoints. Proteins involved in extracellular matrix, gene expression, and DNA-associated functions like DNA repair formed a regeneration-related protein network and were all up-regulated in the dorsal iris. In addition, we investigated protein concentrations in cultured dorsal (transdifferentiation-competent) and ventral (transdifferentiation-incompetent) iris pigmented epithelial (IPE) cells. Our comparative analysis revealed that the ability of dorsal IPE cells to keep memory of their tissue of origin and transdifferentiation is associated with the expression of proteins that specify the dorso-ventral axis of the eye as well as with proteins found highly expressed in regeneration timepoints, especially 8 days post-lentectomy.

Conclusions: The study deepens our understanding in the mechanism of regeneration by providing protein networks and pathways that participate in the process.
\end{abstract}

Keywords: Regeneration, Lens, Newt, Proteomics, Gene expression, Regeneration program

\section{Background}

Several amphibian species own the ability to regenerate multiple different organs during adulthood making them excellent models to study the molecular mechanisms of tissue regeneration. Although regulation of regeneration might diverge among tetrapods, a deeper understanding of regenerative processes in amphibians will provide valuable clues for organ repair and regeneration in other organisms such as mammals $[1,2]$.

Regeneration of the eye lens in newts provides a superb model to study regeneration. After surgical removal of the lens, the whole organ regenerates by transdifferentiation of

\footnotetext{
*Correspondence: ptsonis1@udayton.edu

'Department of Biology and Center for Tissue Regeneration and Engineering at Dayton, University of Dayton, 300 College Park, Dayton, OH 45469, USA Full list of author information is available at the end of the article
}

dorsal iris pigmented epithelial (IPE) cells. Interestingly, the lens is never regenerated from the ventral iris, which provides a number of experimental options [3,4]. Most importantly, gene expression differences between the dorsal and the ventral part of the iris can be identified to unravel the molecular program enabling regeneration. Similarly, changes in the expression profile between the iris while the lens is intact and during lens regeneration allow characterization of regulatory pathways initiating regeneration. In addition, dorsal IPE cells retain their ability to form a lens after in vitro culturing, aggregation, and orthotopic transplantation or implantation into 3-D collagen lattices while ventral IPE aggregates fail to do so. Hence, gene expression profiles of cultured dorsal and ventral IPE cells might provide additional insights into lens regeneration [5]. 
Recently, the first newt transcriptome was assembled, and RNA sequencing of newt iris has been used to study differences in gene expression between the dorsal and ventral iris. Analysis of gene expression identified genes exclusively expressed in either the dorsal or ventral iris as well as genes expressed in a gradient along the dorsoventral axis of the iris during lens regeneration [6,7]. In another study, custom newt microarrays were used to detect 467 genes that were differentially expressed during lens regeneration [8]. Although these studies provided essential information about the expression of genes during newt lens regeneration, protein data were missing so far. Mass-spectrometrybased protein analysis closes this gap providing information about changes in protein concentrations and potential post-transcriptional regulation during lens regeneration. Here, we computed the newt proteome from the assembled transcriptome and performed liquid chromatography followed by tandem mass spectrometry (LC-MS/MS) to identify proteins differentially expressed between dorsal and ventral iris as well as between regenerating and intact iris. We chose to use dorsal and ventral iris 4 and 8 days postlentectomy $(\mathrm{dpl})$ since during these timepoints iris cells reenter the cell cycle and transdifferentiate. We then compared the expression data with the previously reported gene expression data at the mRNA level collected at the same timepoints. In addition, we performed LC-MS/MS with samples collected from in-vitro-cultured dorsal and ventral IPE cells. We compared the expression profiles between the in vitro and in vivo experiments. Lastly, we compared available high-throughput mRNA and protein expression data obtained from amphibian organ model systems undergoing regeneration, identifying a common regeneration program.

\section{Results and Discussion}

\section{LC-MS/MS identifies novel newt proteins}

Lenses were removed from newt eyes in order to initiate the regeneration process at the dorsal iris. Dorsal and ventral iris samples were collected at 4 and $8 \mathrm{dpl}$ as well as from intact tissue (day 0 ). At $4 \mathrm{dpl}$, dorsal and ventral iris cells re-enter the cell cycle while at $8 \mathrm{dpl}$ only dorsal iris cells initiate dedifferentiation. The iris samples were prepared, and LC-MS/MS was performed in order to investigate changes in protein concentrations (Figure 1A). The newly assembled newt transcriptome was used for peptide identification [7]. LC-MS/MS identified 8,167 different proteins. These proteins were uniquely annotated to 4,734 different human proteins (e-value $<1 \mathrm{E}-10$ ). Direct comparisons with proteins found in previous proteomic studies in newts revealed that 701 of these annotated proteins have not been detected in newts before [7]. Our dataset also includes 143 proteins lacking annotations in other species, which raises the possibility that they are unique to

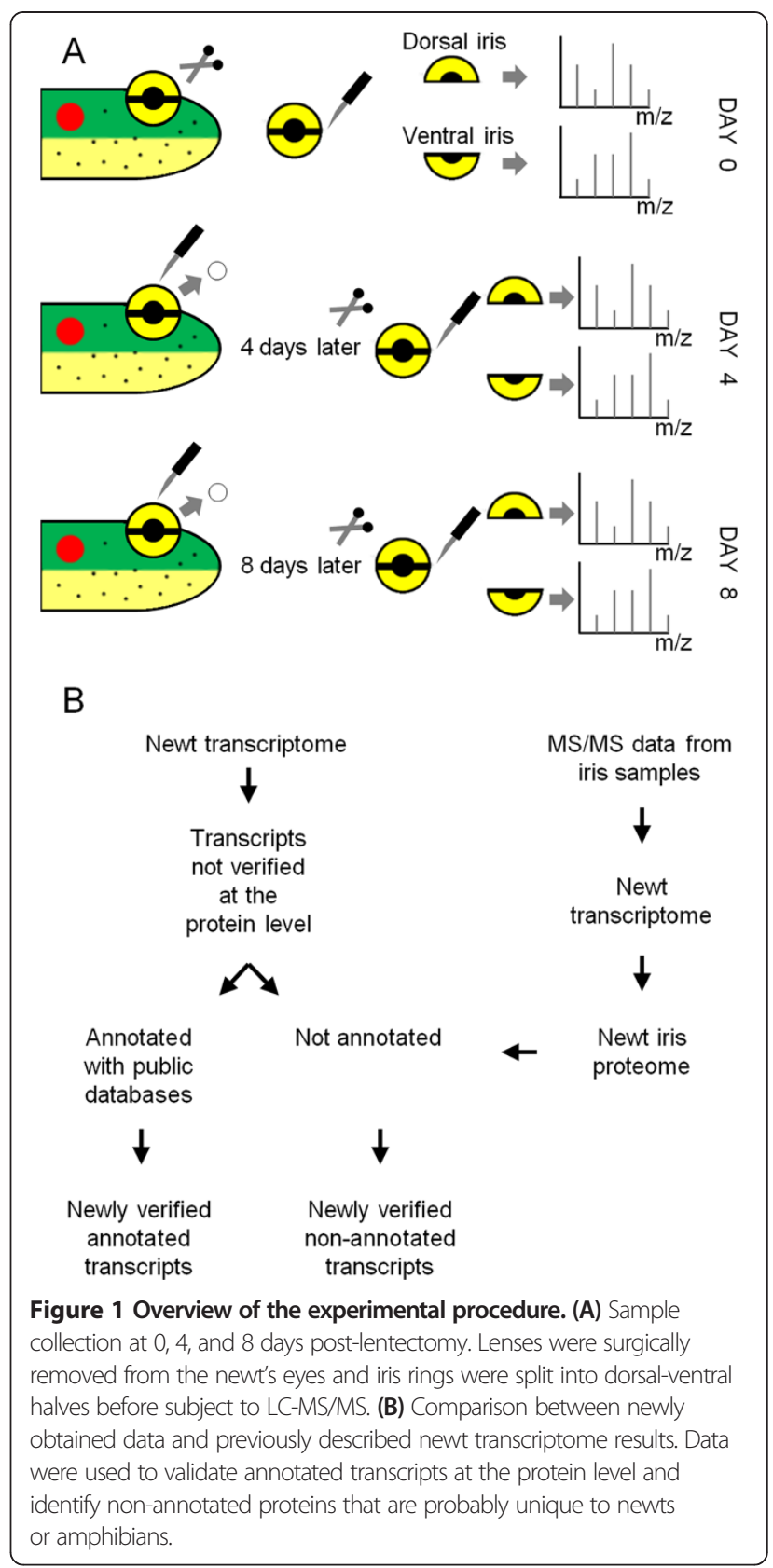

newts. These data are summarized as a whole and per sample in Table 1 (Workflow: Figure 1B).

\section{Protein expression patterns during regeneration}

The primary interest of our study was to identify proteins that might play a role during tissue regeneration. To achieve this goal, we compared proteins that were present at 4 and $8 \mathrm{dpl}$ (both dorsal and ventral iris) and were expressed at least twofold higher than proteins in the intact iris at day 0 (regeneration group). Likewise, we examined proteins that were down-regulated (at least twofold) during regeneration (control group). To investigate the trends that our analysis yielded, we used the gene ontology (GO) terms 
Table 1 Number of annotated and non-annotated proteins found by LC-MS/MS

\begin{tabular}{|c|c|c|c|c|c|c|c|}
\hline & \multirow[b]{2}{*}{ Total $^{\mathrm{a}}$} & \multicolumn{2}{|l|}{ Day 0} & \multicolumn{2}{|l|}{ Day 4} & \multicolumn{2}{|l|}{ Day 8} \\
\hline & & Dorsal & Ventral & Dorsal & Ventral & Dorsal & Ventral \\
\hline Proteins expressed & 8,167 & 3,454 & 4,899 & 4,082 & 3,616 & 4,474 & 5,374 \\
\hline New verified proteins & 1,479 & 248 & 604 & 361 & 285 & 436 & 682 \\
\hline Human proteins expressed & 4,734 & 2,638 & 3,425 & 2,997 & 2,705 & 3,269 & 3,621 \\
\hline New verified human proteins & 701 & 150 & 333 & 199 & 159 & 242 & 353 \\
\hline New verified newt proteins & 143 & 13 & 37 & 29 & 30 & 28 & 54 \\
\hline
\end{tabular}

Values are given per sample and for all experiments together.

anon-redundant.

of the annotated proteins and we performed enrichment analysis using Fisher's exact test corrected for multiple selections between the regeneration and control groups (false discovery rate, FDR $<0.05$; Figure $2 \mathrm{~A}$ ). Metabolic process and gene expression were some of the GO terms enriched during regeneration in both dorsal and ventral iris samples while the GO term "cell periphery" was enriched in the control samples (Figure 2B and Additional file 1). Tables 2 and 3 (for dorsal iris) and Tables 4 and 5 (for ventral iris) list the genes reflecting the $\mathrm{GO}$ term enrichments for the regeneration group. These genes determine cellular functions in response to stress and reactive oxygen species. They are also involved in the regulation of translation, RNA maturation, and immune responses. Genes that were induced in the iris post-lentectomy can be grouped per function as follows:

\section{a. Gene expression}

Elongation factor 1-delta (EEF1D), elongation factor 1gamma (EEF1G), valine-tRNA ligase, and ribosomal proteins RPL10, RPL13, RPL18A, RPL27A, RPL3, RPL4, RPL5, RPS23, and RPS8 are all known for their role in the translation of proteins. RNA-processing proteins include poly(U)-specific endoribonuclease (ENDOU), nucleasesensitive element-binding protein 1 (YBX1), which is also implicated in cell proliferation [9], pre-mRNA-processingsplicing factor 8 (PRPF8), and probable ATP-dependent RNA helicase DDX5. In addition, two members of the ribonucleoprotein complex (ARC), polyadenylate-binding protein 1 (PABPC1) and cold shock domain-containing protein E1 (CSDE1), were detected. Consistent with these results, previous studies in mice have found PABPC1 to be up-regulated during liver regeneration [10]. Similarly, another stress-induced RNA processing protein, the heat shock cognate $71 \mathrm{kDa}$ protein (HSPA8), was found to play a role during rat skeletal muscle regeneration and zebrafish caudal fin regeneration $[11,12]$.

Basic leucine zipper and W2 domain-containing protein 1 (BZW1), protein arginine $\mathrm{N}$-methyltransferase 5 (PRMT5), and SWI/SNF-related matrix-associated actin-dependent regulator of chromatin subfamily A member 5 (SMARCA5) are known for regulation of gene expression. Interestingly, BZW1 has been previously found to induce histone $\mathrm{H} 4$ gene expression, which aids the progression of the G1/S phase of the cell cycle [13]. In addition, PRMT5 has been shown to play role in cell proliferation in planaria and be up-regulated post-injury in the kidneys [14,15]. Methionine aminopeptidase 1 (METAP1) and receptor-type tyrosine-protein phosphatase C (PTPRC), also known as CD45, have been shown to play a role in cell activation, proliferation, and cell cycle progression [16-18]. The protein expression data implicate regulation of gene expression as an important event for transdifferentiation.

\section{b. ROS balance}

Heme oxygenase 1 (HMOX1), redox-regulatory protein FAM213A, cis-aconitate decarboxylase (IRG1), and serpin B10 (SERPINB10) are known for their association with reactive oxygen species (ROS) and redox balance. IRG1 is activated by ROS to prevent infections [19]. SERPINB10 plays a role in protein processing and it is sensitive to redox stress [20]. HMOX1 is induced by ROS and has been linked to wound healing and regeneration in many regeneration model systems with the exception of mouse liver regeneration [21-24]. ROS stress and redox balance has gained a lot of attention since many studies have associated changes related to them with regenerative responses [25]. Our data indicate a potential role of ROS during newt lens regeneration as well.

\section{c. Immune response}

Argininosuccinate synthase (ASS1), complement factor B (CFB), acidic mammalian chitinase (CHIA), bis (5'adenosyl)-triphosphatase ENPP4, eosinophil peroxidase (EPX), coagulation factor XIII A chain (F13A1), and myeloperoxidase (MPO) are up-regulated during lens regeneration and are known for their roles in preventing infections and generally to facilitate host defense and immune response. 


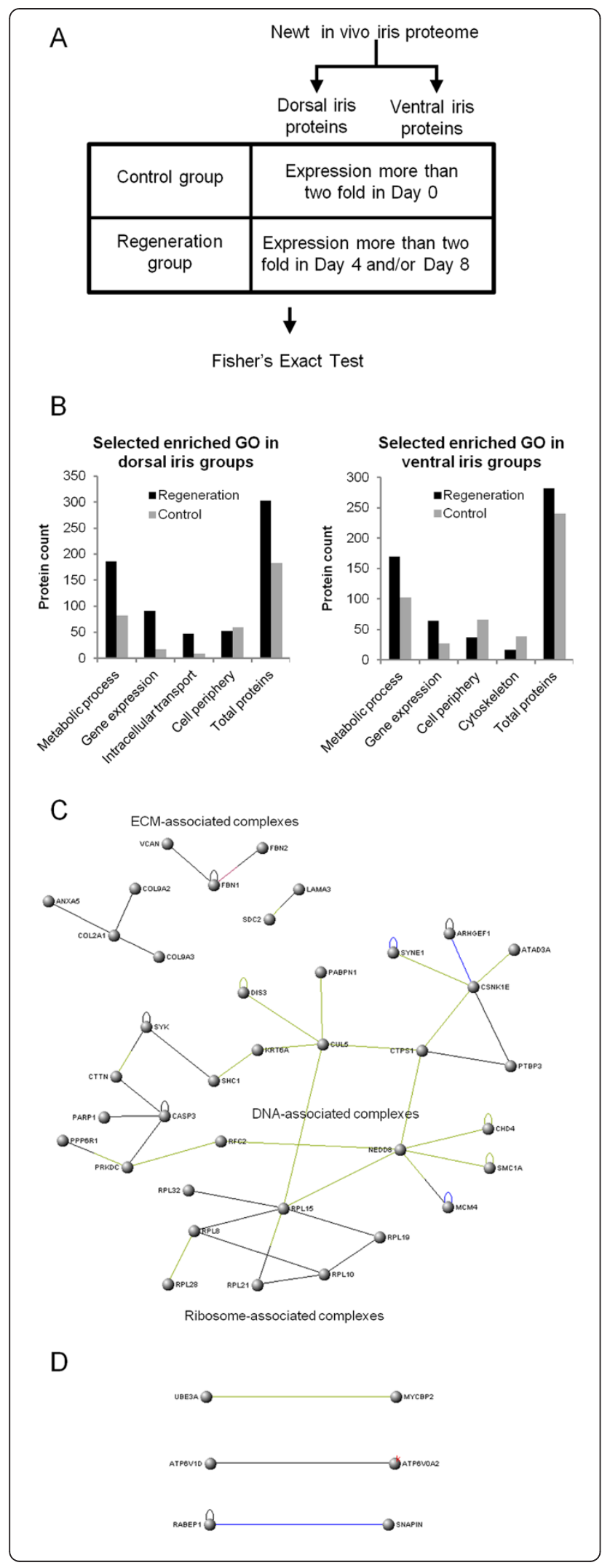

Figure 2 Comparisons between regenerating and control samples. (A) Workflow for selecting control and regeneration groups for Fisher's exact test. (B) Selected enriched gene ontology $(\mathrm{GO})$ terms $(\mathrm{FDR}<0.05)$ in regeneration or control groups for dorsal and ventral samples. Bars indicate the number of proteins in each group. (C) Network analysis of proteins expressed at higher levels in regenerating and dorsal samples. (D) Network analysis of proteins expressed at higher levels in regenerating and ventral samples. (C, D) Connections between nodes indicate protein-protein interaction. Only proteins that showed at least one interaction with another protein of the same group were displayed.

\section{d. Metabolic processes}

Sterol O-acyltransferase 1 (SOAT1), delta-1-pyrroline-5carboxylate synthase (ALDH18A1), v-type proton ATPase subunit d 1 (ATP6V0D1), cytochrome b-245 heavy chain (CYBB), n-acylethanolamine-hydrolyzing acid amidase (NA $\mathrm{AA})$, putative neutrophil cytosol factor $1 \mathrm{C}$ (NCF1C), neutrophil cytosol factor 2 (NCF2), and 6-phosphogluconate dehydrogenase, decarboxylating (PGD) participate in many metabolic processes and regulation of energy production. SOAT1 is also known to be involved during rat adrenal regeneration [26].

\section{e. Other functions}

Additional interesting proteins, potentially involved in the regulation of newt lens regeneration, are msx2interacting protein (SPEN), which aids wound healing in Drosophila embryos [27]; cathepsin L1 (CTSL1), which mediates proteolysis; DNA topoisomerase 1 (TOP1), which is associated with DNA replication and transcription; epidermal retinol dehydrogenase 2 (SDR16C5), which is involved in making retinoic acid; and ATP-dependent DNA helicase Q1 (RECQL), which mediates DNA repair. Furthermore, we found an up-regulation of unconventional myosinXVIIIa (MYO18A), which is involved in cell migration, as well as fibronectin (FN1) and integrin beta-2 (ITGB2), which mediate adhesion and cell migration and are essential for zebrafish heart regeneration [28].

The rapid up-regulation of all the aforementioned proteins during lens regeneration clearly underscores the importance of host defense, redox balance, and response to stress for the initiation of regeneration.

\section{Proteins regulated in dorsal versus ventral iris}

Since regeneration only proceeds from the dorsal iris, we wanted to find proteins that were specifically up-regulated in this tissue. To achieve this goal, we compared all proteins up-regulated during lens regeneration to proteins only up-regulated in the dorsal or the ventral iris. Proteins identified were imported in VisANT, a program that analyses protein-protein interactions [29]. Proteins that were expressed at higher levels in dorsal samples represented 


\begin{tabular}{|c|c|c|c|c|c|c|c|}
\hline \multicolumn{8}{|c|}{ GO:0010467; gene expression and parental GO } \\
\hline \multicolumn{6}{|c|}{ Dorsal regeneration } & \multicolumn{2}{|c|}{ Dorsal control } \\
\hline AARS & ENDOU & KHSRP & RPL10A & RPLP2 & SNRNP70 & AHCYL2 & GJA1 \\
\hline ANK3 & ETF1 & KIAA1967 & RPL13 & RPS2 & SOAT1 & BACE2 & KANK2 \\
\hline BUD31 & FUBP1 & LUC7L3 & RPL13A & RPS23 & SPEN & CAV1 & KRT17 \\
\hline BZW1 & GARS & METAP1 & RPL18 & RPS24 & SSB & CCDC88C & MPP6 \\
\hline C3 & GCN1L1 & MTA2 & RPL18A & RPS28 & SUGP2 & CRK & NEO1 \\
\hline CSDE1 & GLG1 & MTOR & RPL19 & RPS4X & SUPT16H & EEF1A1 & PSMB9 \\
\hline DAD1 & HBS1L & PABPC1 & RPL21 & RPS5 & TARS & EIF4H & PTRF \\
\hline DDX17 & $\mathrm{HCK}$ & PES1 & RPL26 & RPS6 & TMED2 & FHL2 & RBCK1 \\
\hline DPM1 & HMOX1 & POLR2A & RPL27A & RPS8 & U2AF1L4 & FKBP9 & STAT5B \\
\hline EEF1D & HNRNPM & POLR2E & RPL28 & RPS9 & UBE2I & & \\
\hline EEF1G & HNRNPU & PPP2R5C & RPL3 & SERBP1 & VARS & & \\
\hline EEF2 & HSPA8 & PRMT5 & RPL35 & SLTM & WDR77 & & \\
\hline EIF3B & ILF3 & PRPF8 & RPL4 & SMARCA5 & WFS1 & & \\
\hline EIF4G2 & IPO9 & РТВP3 & RPL5 & SMC1A & YARS & & \\
\hline EIF5A & KHDRBS1 & RPL10 & RPL8 & SND1 & YBX1 & & \\
\hline \multicolumn{8}{|l|}{ EIF5B } \\
\hline
\end{tabular}

complexes associated with extracellular matrix, ribosomes, and DNA (Figure 2C) whereas proteins expressed at higher levels in ventral samples did not exhibit such a pattern (Figure 2D).

\section{a. Extracellular matrix}

Collagen proteins such as COL2A1, COL9A2, and COL9A3 are essential for structural support and provide the substrate for surrounding cells. In addition, COL9A2 and COL9A3 compose the vitreous area of the eye. Versican core protein (VCAN) is known for cell-extracellular matrix interactions allowing cell migration and growth. Laminin subunit alpha-3 (LAMA3) promotes migration. Fibrillin-1 (FBN1), fibrillin-2 (FBN2), and syndecan-2 (SDC2) are extracellular matrix proteins regulating the availability of growth factors to nearby cells. SDC2 also plays a role during rat periodontal wound healing [30]. Annexin A5 (ANXA5) is known for its anticoagulant properties and promotes wound healing in the cornea [31]. Previous studies in newt limb and lens regeneration also support these findings. A study in newt limb regeneration suggests that dynamic changes of the extracellular matrix provide a suitable microenvironment for regeneration [32], which is in-line with the up-regulation of several extracellular matrix genes during newt lens regeneration in the dorsal iris as determined by DNA microarray analysis [8]. These results suggest that remodeling an appropriate environment is a fundamental event during lens regeneration.

\section{b. Cell activation}

Rho guanine nucleotide exchange factor 1 (ARHGEF1), ATPase family AAA domain-containing protein 3A (ATAD3A), polypyrimidine tract-binding protein 3 (PTBP3, also known as ROD1), casein kinase I isoform epsilon (CSNK1E), src substrate cortactin (CTTN), replication factor $\mathrm{C}$ subunit 2 (RFC2), and NEDD8 have all been shown to have roles in cell proliferation, migration, and growth [33-36]. These cellular events are important since the lost tissue needs to be regenerated.

\section{c. Gene expression}

Cullin-5 (CUL5), polyadenylate-binding protein 2 (PAB PN1), exosome complex exonuclease RRP44 (DIS3), SHCtransforming protein 1 (SHC1), tyrosine-protein kinase SYK, serine/threonine-protein phosphatase 6 regulatory subunit 1 (PPP6R1), chromodomain-helicase-DNA-binding protein 4 (CHD4), and ribosomal proteins RPL15, RPL32, RPL8, RPL28, RPL21, RPL10, and RPL19 are playing roles in regulating gene expression at various levels [37] and are all up-regulated in the dorsal iris. Interestingly, CHD4 has also been shown to be up-regulated during muscle regeneration in mice [38]. RNA sequencing during lens regeneration has previously revealed that genes associated with the regulation of gene expression are enriched in the dorsal iris, a pattern that we also found here at the protein level [6]. These results highlight the importance of rapid and impactful changes in the 
Table 3 Genes with GO term related to metabolic process that are up-regulated in the dorsal iris during regeneration versus control

\begin{tabular}{|c|c|c|c|c|c|c|c|}
\hline \multicolumn{8}{|c|}{ GO:0008152; metabolic process and parental GO } \\
\hline \multicolumn{4}{|c|}{ Dorsal regeneration } & \multicolumn{4}{|c|}{ Dorsal control } \\
\hline AASS & CYB5B & HSD17B13 & PPID & ABAT & $\mathrm{CP}$ & ITPR2 & PTPRA \\
\hline ACTN1 & CYBA & HSP90AB1 & PPP3CC & ABCB7 & CTSS & LANCL1 & PTPRD \\
\hline AFG3L2 & CYBB & HSP90B1 & PSMD1 & ACAD10 & CYP2A6 & LTA4H & RAB27B \\
\hline AKAP8L & DDX5 & HSPA5 & PTPRC & ACOT2 & DCN & MAOA & RAB7A \\
\hline ALDH16A1 & DNAJA1 & HSPA9 & RAD23A & AGL & DCTN1 & MINPP1 & RECK \\
\hline ALDH18A1 & DNPEP & |RG1 & RASA4 & AK4 & DHRS2 & MRI1 & SDHAF2 \\
\hline ALDOC & DPP3 & ITGB2 & RECQL & AKR1C4 & $\mathrm{ECHS1}$ & MYH11 & SDHD \\
\hline ALOX5AP & DSP & ITPR2 & $\mathrm{RHO}$ & ALDH3B1 & EHD2 & MYO5A & SH3GLB1 \\
\hline APMAP & DUSP11 & LMNA & SCD5 & ANXA1 & ENTPD2 & NEU3 & SPTBN1 \\
\hline APOA 1 & ELOVL1 & MAP3K15 & SDHC & $\mathrm{AOC} 3$ & FABP3 & NPR3 & SULT1B1 \\
\hline ASS1 & ENPP4 & MARCKS & SDR16C5 & APPL2 & GAPVD1 & NRP1 & SULT1C2 \\
\hline ATP2A2 & ENTPD8 & MPO & SERPINB10 & ATP13A5 & GGT5 & PARG & TPM1 \\
\hline ATP6V0D1 & EPX & MYO18A & SLC25A12 & CDC42BPB & GRHPR & PGM5 & TPP1 \\
\hline ATP6V1A & ERO1L & NAAA & SLC9A3R1 & CECR1 & GSTZ1 & PIPOX & TUBB3 \\
\hline BIN1 & $\mathrm{F} 13 \mathrm{~A} 1$ & NAT8B & SQRDL & CLPX & $\mathrm{HIBCH}$ & PPIC & YWHAG \\
\hline CANX & FAM213A & NCF1C & TIMM50 & & & & \\
\hline CFB & FN1 & NCF2 & TNFAIP8 & & & & \\
\hline $\mathrm{CHIA}$ & GNS & NUP93 & TOP1 & & & & \\
\hline COL3A1 & GPD1L & PCCA & UBLCP1 & & & & \\
\hline COX7A2L & GSTP1 & PDPR & UQCRB & & & & \\
\hline CPT1A & H6PD & PFKP & USP5 & & & & \\
\hline CTSL1 & HK1 & PGD & VRK1 & & & & \\
\hline CUL3 & HM13 & & & & & & \\
\hline
\end{tabular}

regulation of gene expression that will ultimately lead to transdifferentiation of iris cells to lens cells.

\section{d. DNA repair}

Poly [ADP-ribose] polymerase 1 (PARP1), DNAdependent protein kinase catalytic subunit (PRKDC), and structural maintenance of chromosomes protein 1A (SMC1A) have known roles in DNA repair. DNA repair genes such as RAD1 have been previously found to be up-regulated in the dorsal iris using both microarrays and RNA sequencing during newt lens regeneration $[6,8]$. Such cellular machinery can play a role in maintaining the integrity of the genome an important aspect of regenerating an exact "clone" of the missing lens.

\section{e. Other functions}

Other proteins found to be up-regulated in the dorsal iris during lens regeneration were keratin, type II cytoskeletal 6A (KRT6A), and caspase-3 (CASP3) which have been implicated in wound healing and regeneration $[39,40]$.

All these proteins, grouped in the different functional categories, were up-regulated in the dorsal compared to the ventral iris during lens regeneration. Interestingly, several of these proteins formed interacting networks that can be linked to the regeneration process (Figure 2C).

\section{Validation of changes in expression levels by qPCR}

Since only few newt specific antibodies are available, we used quantitative real-time polymerase chain reaction (qPCR) to validate our data. Although qPCR measures mRNA and not protein concentrations, we reasoned that concomitant changes at the mRNA and protein levels might allow us to validate general patterns of gene activity during regeneration. We selected several proteins based on their putative function. Retinal dehydrogenase 1 (ALDH1A1), ephrin-B1 (EFNB1), and ephrin-B2 (EFNB2) were significantly up-regulated in the dorsal iris compared to the ventral irrespective of the timepoint $(p<0.05$; 
Table 4 Genes with GO term related to gene expression that are up-regulated in the ventral iris during regeneration versus control

GO:0010467; gene expression and parental GO

\begin{tabular}{|c|c|c|c|c|c|c|c|}
\hline \multicolumn{6}{|c|}{ Ventral regeneration } & \multicolumn{2}{|c|}{ Ventral control } \\
\hline AARSD1 & EIF3J & PFDN5 & RPL27A & RQCD1 & THBS1 & CAT & ILK \\
\hline ATP6AP2 & ENDOU & POLR1C & RPL3 & SEC11A & UBTF & CD44 & KANK2 \\
\hline BZW1 & GALNT12 & PRKCl & RPL38 & SMARCA5 & VARS & $\mathrm{CDH} 13$ & KRT17 \\
\hline CARS & HBS1L & PRMT5 & RPL4 & SNF8 & VIPAS39 & CHMP1A & PRKCA \\
\hline CSDE1 & HMOX1 & PRPF8 & RPL5 & SNRPE & WARS & $\operatorname{cog} 2$ & PRKDC \\
\hline DDX39A & HSPA8 & PSME3 & RPS13 & SOAT1 & WDR61 & COL4A6 & PURA \\
\hline DNAJC2 & KDM1A & RCL1 & RPS15 & SPEN & WTAP & CTNNB1 & RBCK1 \\
\hline EBNA1BP2 & MARS & RPL10 & RPS17 & SRSF12 & YBX1 & DEK & SBDS \\
\hline EEF1B2 & METAP1 & RPL13 & RPS23 & SSR4 & YLPM1 & DMD & SEC31A \\
\hline EEF1D & NPC1 & RPL17 & RPS27 & SUPT6H & & EXOSC7 & UGGT2 \\
\hline EEF1G & PABPC1 & RPL18A & RPS8 & TGFB1 & & GJA1 & VPS36 \\
\hline
\end{tabular}

Table $\mathbf{5}$ Genes with GO term related to metabolic process that are up-regulated in the ventral iris during regeneration versus control

\begin{tabular}{|c|c|c|c|c|c|c|c|}
\hline \multicolumn{8}{|c|}{ GO:0008152; metabolic process and parental GO } \\
\hline \multicolumn{4}{|c|}{ Ventral regeneration } & \multicolumn{4}{|c|}{ Ventral control } \\
\hline ABCF2 & $\mathrm{DCN}$ & LARP1 & PRRC1 & ABCB5 & ECHDC2 & NIT2 & SLC22A2 \\
\hline ACSBG2 & DDX5 & LYN & PRSS16 & $\mathrm{ADH} 4$ & EHD2 & OXCT1 & SLC9A3R2 \\
\hline $\mathrm{ACY} 1$ & DGAT1 & LYZ & PRTN3 & AGL & F8 & PI4KA & SOD1 \\
\hline $\mathrm{ADH} 1 \mathrm{~B}$ & DNAJB11 & MCM5 & PTPN6 & AK4 & FAM162A & PLCG1 & SULT1B1 \\
\hline ALDH18A1 & DNM2 & MCM6 & PTPRC & ALG11 & FBN1 & PNP & SULT1C2 \\
\hline ALDH1A3 & $\mathrm{ECl} 2$ & MDN1 & PZP & ATAD1 & GALE & PNPO & SYTL2 \\
\hline ALOX5 & ECM1 & MOB1B & RCC1 & ATG7 & GLUL & PRKAB1 & TGM1 \\
\hline ALPL & ENPP4 & MPDU1 & RECQL & C6orf130 & GMPR2 & PRKAR2B & TPP1 \\
\hline ARAP1 & EPX & MPO & RFC5 & CAPN5 & GNA14 & PTGR1 & TTLL12 \\
\hline ASS1 & F13A1 & MYO18A & RNF213 & CDIPT & GNAl1 & PTK2 & TUBB3 \\
\hline ATP2A1 & FAM213A & MYO5A & RNLS & CECR1 & GRHPR & PTPLAD1 & VCP \\
\hline ATP6V0D1 & FASN & NAAA & SDR16C5 & CLYBL & $\mathrm{HAGH}$ & PTPRD & XPNPEP1 \\
\hline ATP6V1F & FBP1 & NADKD1 & SERPINB10 & COPS3 & HIST1H2AG & PYGB & \\
\hline C3 & FEN1 & NCF1C & SERPINB6 & $\mathrm{CP}$ & HMOX2 & RAB27B & \\
\hline CFB & FKBP4 & NCF2 & SGPP1 & CTSS & KLC4 & RAB3D & \\
\hline $\mathrm{CHIA}$ & FN1 & NCKAP1L & SLC25A40 & CUL5 & LANCL1 & RAB7A & \\
\hline CKM & GBF1 & NMT2 & SMPD3 & CYP2A13 & MARCKS & RABGAP1 & \\
\hline CNEP1R1 & GCAT & NRAS & SQSTM1 & CYP2J2 & MTCH1 & RGN & \\
\hline COX5B & GCLM & NUP155 & SYK & DCTN1 & MT-CYB & RTN4IP1 & \\
\hline $\mathrm{CP}$ & GLB1 & NUP210 & TBC1D9B & DLG1 & MYH11 & SEPHS1 & \\
\hline CTSA & GLUL & $\mathrm{P} 2 \mathrm{RX} 4$ & TOP1 & DMGDH & NDUFB4 & SERPINI1 & \\
\hline CTSL1 & HECTD1 & PAFAH1B2 & UNC45A & & & & \\
\hline CUL2 & $\mathrm{HIST} 2 \mathrm{H} 2 \mathrm{AB}$ & PGD & USP24 & & & & \\
\hline CYBB & IDE & PLD3 & WWA8 & & & & \\
\hline CYP4F22 & IRG1 & PNP & WBSCR22 & & & & \\
\hline CYP7B1 & ITGB2 & & & & & & \\
\hline
\end{tabular}



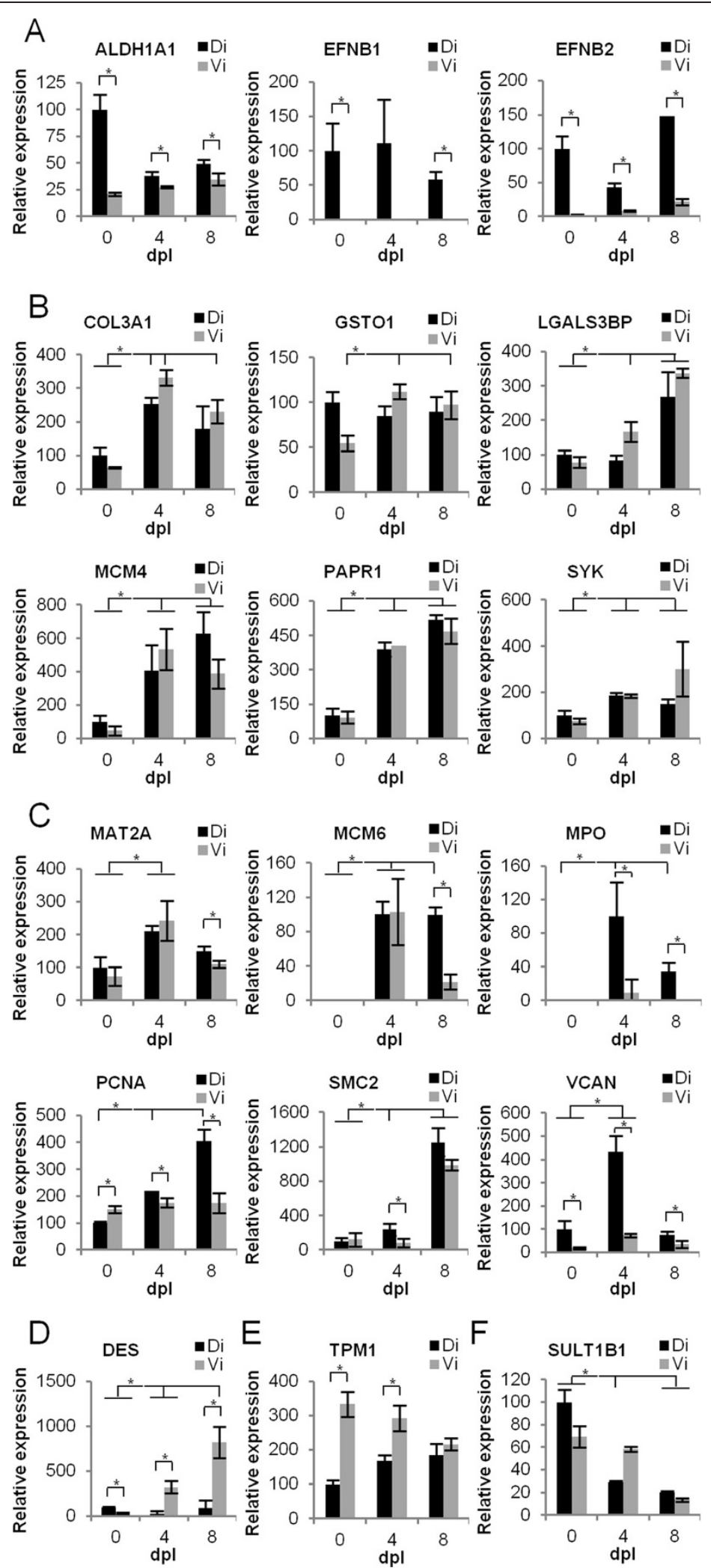

Figure $\mathbf{3}$ (See legend on next page.) 
(See figure on previous page.)

Figure 3 Validation of protein expression data by qPCR analysis. (A) Genes expressed at higher levels in dorsal iris. (B) Genes expressed at higher levels during regeneration. (C) Genes expressed at higher levels in the dorsal iris and during regeneration. (D) Gene expressed at higher levels in the ventral iris and during regeneration. (E) Gene expressed at higher levels in the ventral iris. (F) Gene expressed at higher levels in the intact iris. Student's $t$-test for independent samples was used for statistical significance. Homoscedasticity was assumed when Levene's test $p$ value was greater than 0.05 . Asterisk $\left(^{*}\right)$ indicates statistical significance (Student's $t$-test; $p<0.05$ ). Each bar represents the average of triplicate values. Error bars represent standard deviation. Lines on the top of the graph compare samples during regeneration and control. Lines on the top of bars corresponding to a single day compare dorsal and ventral iris. For simplicity, only the statistics relevant for each group are presented on the graphs.

Figure 3A). Interestingly, these genes are also expressed during eye development in the dorsal optic cup [41,42] revealing a persisting pattern of gene expression from embryonic development to adulthood in the iris of newts. It is tempting to speculate that such genes may aid or repress regeneration hence providing the intrinsic regeneration potential of the dorsal iris. COL3A1, glutathione S-transferase omega-1 (GSTO1), galectin-3-binding protein (LGALS3BP), DNA replication licensing factor MCM4, PARP1, and SYK were up-regulated during regeneration both in the ventral and the dorsal parts of the iris $(p<0.05$; Figure 3B). These genes are related to extracellular matrix, cell adhesion, redox balance, DNA maintenance, and DNA repair, processes required for regeneration and wound repair. S-adenosylmethionine synthase isoform type-2 (MAT2A), DNA replication licensing factor MCM6, MPO, proliferating cell nuclear antigen (PCNA), structural maintenance of chromosomes protein 2 (SMC2), and VCAN are also associated with the above-mentioned cellular processes but showed a higher expression in the dorsal versus the ventral iris and were expressed at higher levels during regeneration compared to undamaged controls $(p<0.05$; Figure $3 \mathrm{C}$ ) suggesting that the dorsal iris responds more robustly than the ventral iris to regenerative cues. Desmin (DES) is an intermediate filament found mostly in muscle tissue and has been associated with mitochondrial dysfunction and elevated ROS [43]. Desmin is only up-regulated during regeneration in the ventral iris $(p<0.05$; Figure 3D). Tropomyosin alpha-1 chain (TPM1) is another cytoskeleton protein up-regulated in the ventral iris compared to the dorsal iris $(p<0.05$; Figure 3E). Lastly, sulfotransferase family cytosolic $1 \mathrm{~B}$ member 1 (SULT1B1), an enzyme catalyzing sulfonation, was expressed at higher levels in the intact iris (day 0), an expression pattern also found during liver regeneration in rats (Figure 3F) [44]. Overall, the qPCR data corroborated the expression changes found at the proteome level by mass spectrometry.

\section{Protein expression patterns from the in vitro proteome}

IPE cells retain their ability to transdifferentiate to lens cells in vitro, a process that can take up to 2 weeks. After re-aggregation and transplantation into a lentectomized eye, only the dorsal but not ventral iris aggregates transdifferentiate to lens cells [45]. Similarly, only dorsal aggregates will transdifferentiate rapidly within 1-2 weeks to a structured lens when placed in 3-D collagenbased lattices like Matrigel [5]. Intriguingly, even IPE cells from higher animals, including humans, can be induced to transdifferentiate into lentoids (not structured lens) under certain culturing conditions [46]. We therefore examined protein expression in cultured IPE cells from the dorsal and ventral iris to monitor potential changes in the state of IPE cells (Figure 4A). In particular, we wanted to know whether culturing changed the protein profile of IPE cells and to identify markers that reflect transdifferentiation.

In total, we identified 2,269 annotated to known human proteins (e-value $<1 \mathrm{E}-10)$ in the cultured IPE cells. Proteins showing more than twofold higher expression either in the dorsal or ventral IPE cells are listed in Additional file 2. Numerous proteins were exclusively found either in the dorsal or ventral IPEs although GO terms analysis only revealed enrichment of cytoskeletonassociated terms in ventral versus dorsal IPE cells (Additional file 1 and Figure 4B).

Next, we compared the in vitro proteome with the in vivo proteome of 0,4 , and $8 \mathrm{dpl}$. Proteins with a similar expression pattern in respect to the dorsoventral axis under both in vitro and in vivo conditions are shown in Table 6. Some proteins have cell cycle, DNA replication, and splicing functions in the cell. EFNB1, DES, ALDH1A1, $\mathrm{SMC} 2$, and MCM4 proteins showed differences in expression levels between the dorsal and ventral IPE cells, an exact pattern as of their protein expression in vivo. As potential dorsoventral markers, we further validated these expression data by qPCR (Figure 4C). EFNB1, ALDH1A1, SMC2, and MCM4 were significantly up-regulated in dorsal IPE cells, while expression of DES was significantly up-regulated in ventral IPE cells $(p<0.05$; Figure $4 C)$. ALDH1A1, SMC2, and DES, which are similarly regulated in the iris during lens regeneration in vivo (Figure $3 \mathrm{~A}, \mathrm{C}$ ), are involved in retinoic acid synthesis and DNA replication. Such cellular processes have been previously shown to be involved in lens regeneration from the dorsal iris [6,47]. Pearson correlation analysis of in vivo and in vitro datasets revealed that the $R^{2}$ correlation value increased from 0 to 4 $\mathrm{dpl}$ with the highest correlation at $8 \mathrm{dpl}$, indicating cells activated for tissue regeneration (Figure 4D). In contrast, 


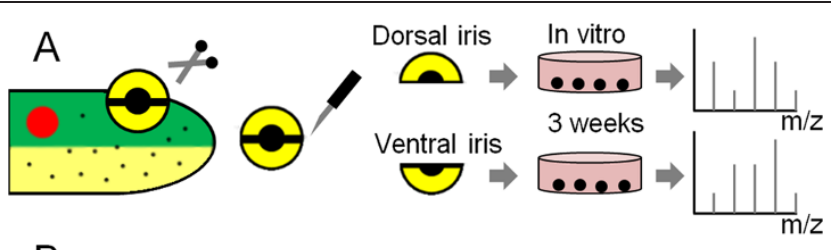

B

Newt iris in vitro proteome
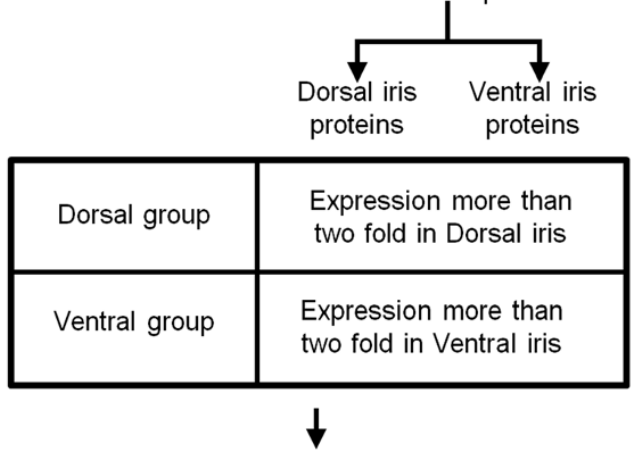

Fisher's Exact Test
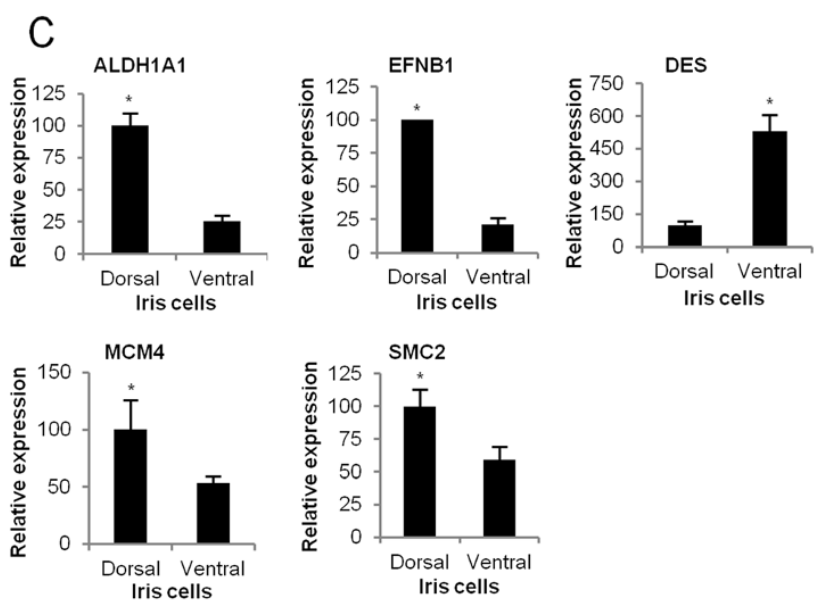

D
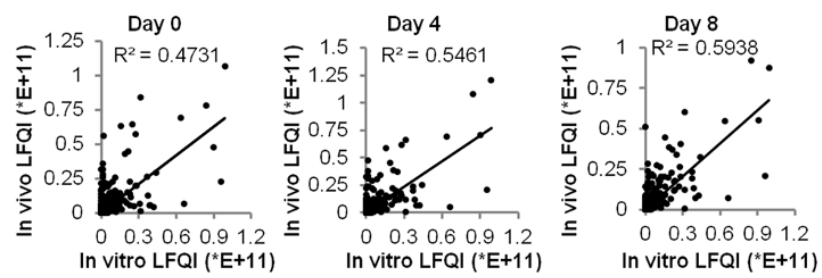

E
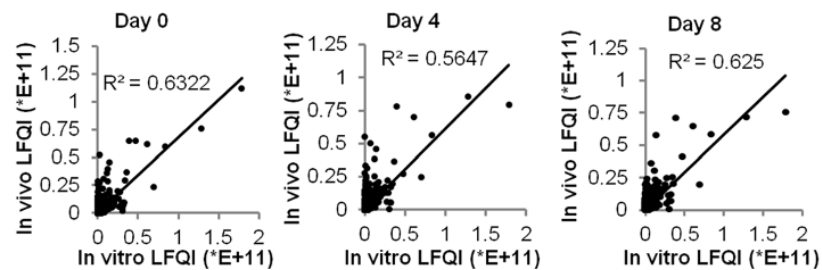

Figure 4 (See legend on next page.) 
(See figure on previous page.)

Figure 4 LC-MS/MS in cultured IPE cells and comparisons with in vivo samples. (A) Overview of procedure for using LC-MS/MS in cultured iris cells. (B) Dorsal and ventral group selection for comparison with Fisher's exact test. (C) qPCR validation of in vitro proteomics data and comparisons. Student's t-test for independent samples was used for statistical significance. Equal variances were assumed when Levene's test $p$ value was greater than 0.05. Asterisk $\left(^{*}\right)$ indicates statistical significance (Student $t$-test; $p<0.05$ ). Each bar represents the average of triplicate values. Error bars represent standard deviation. (D) Pearson correlation between expression of dorsal in vivo proteins at indicated days and expression of dorsal in vitro cultured cell proteins. (E) Pearson correlation between expression of proteins in vivo in the ventral iris at indicated days and expression of proteins in cultured ventral IPE cells.

ventral IPE cells did not show such a correlation or trend (Figure 4E). The expression of dorsal markers ALDH1A1 and EFNB1 in dorsal IPE cells showed that they keep a "memory" of their origin, which consequently might be responsible for their ability to transdifferentiate to lens cells. The identified dorsal- or ventral-specific proteins might be used as markers in high-throughput screening using small molecules to identify agents inducing regeneration.

\section{On the road for a common regeneration program}

During the last two decades, several high-throughput methods including microarrays, next-generation RNA sequencing, and mass spectrometry have been developed to characterize gene expression profiles. We have used datasets from several different studies investigating organ regeneration in amphibians and extracted genes that were expressed at higher levels during tissue regeneration compared to intact controls. We focused on genes that were expressed more than twofold at any regeneration timepoint compared to intact tissue (for more information, see the "Methods" section). In addition, we annotated the genes based on human gene names serving as a common reference for the comparisons. Our search included seven microarray datasets from newt brain, spinal cord, hindlimb, forelimb, lens, heart and tail regeneration, one microarray and one RNA-seq dataset from axolotl limb regeneration $[48,49]$, and two LC-MS/MS studies in newt heart regeneration and axolotl hindlimb regeneration [50-52]. We compared these datasets to proteins upregulated at least twofold in the dorsal iris during lens regeneration compared to intact iris (Figure 5 and Additional file 3). Surprisingly, the highest degree of similarity was found when RNA-seq data from limb regeneration were used (Table 7) [49]. Genes which were jointly activated in these, rather different, tissues during regeneration (Figure 5 and Table 7 ) most likely represent a part of

Table 6 Genes with a similar expression pattern between iris during in vivo lens regeneration and in vitro cultured iris cells

\begin{tabular}{llllllll}
\hline Dorsal & & & & & & Ventral \\
\hline PHPT1 & DDX46 & DDX23 & CHD4 & CDK1 & VCAN & SMC2 & PLEC \\
MCM4 & ALDH1A1 & RANGAP1 & APEH & PUS7 & P4HA1 & GSTO1 & DES \\
PCNA & PARP1 & MAT2A & SPTBN1 & & & & \\
\hline
\end{tabular}

a canonical regeneration program. Hallmarks of the program include inflammation for host defense and cell activation, proliferation of new cells to replace lost tissue, migration for rearrangement of cells, generation of an appropriate extracellular matrix, regulation of ROS and DNA repair for tissue homeostasis, metabolic processes for cells to meet the needs of energy-consuming cellular processes, and changes in gene expression to shape the newly formed organ. We assume that these functional groups play a decisive role in the majority of all regeneration events.

\section{Conclusions}

In this study, we employed LC-MS/MS to identify proteins that are highly expressed during newt lens regeneration. Some of these proteins have similar functions and are arranged in protein networks associated with regulation of the extracellular matrix, DNA repair and maintenance, gene expression, and regulation of translation. Comparisons to other datasets collected during regeneration of a variety of different tissues from amphibians species revealed a putative canonical regeneration program, which seems to be required for regeneration to occur. Finally, we showed that cultured dorsal IPE cells in vitro maintain a molecular memory of their origin and show similar patterns as the 8-dpl in vivo lens regeneration dorsal iris. Taken together, our study provides information about proteins and protein groups that play an important role during tissue regeneration and deepens our understanding of the mechanism of regeneration.

\section{Methods}

\section{Animal procedures}

Animal handling and operations have been described previously [6,45]. Adult newts, Notophthalmus viridescens, were purchased from the Charles Sullivan Inc. Newt Farm. Anesthesia was performed with $0.1 \%(w / v)$ ethyl-3-aminobenzoate methanesulfonic acid (MS222; Sigma-Aldrich, St. Louis, MO) in phosphate buffered saline (PBS; $37 \mathrm{mM} \mathrm{NaH} \mathrm{PO}_{4}$ monohydrate, $58 \mathrm{mM}$ $\mathrm{Na}_{2} \mathrm{HPO}_{4}$ anhydrous, $\mathrm{pH}$ 7.0). All procedures involving animals were approved by the University of Dayton Institutional Animal care and Use Committee. 


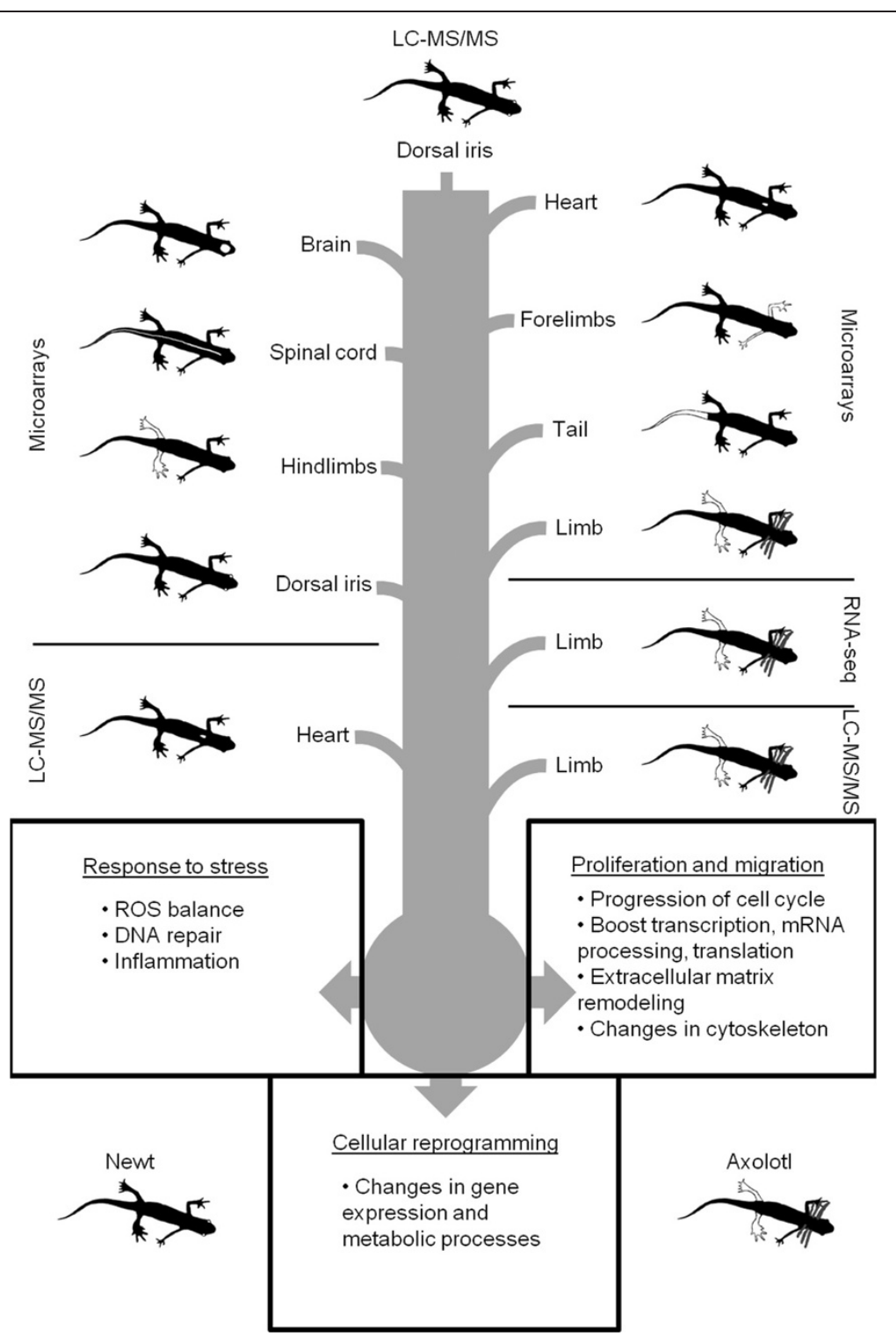

Figure 5 Gene expression comparison of different regenerating tissues from amphibians reveals a canonical regeneration program. Proteins found to be up-regulated during regeneration in the dorsal iris in the present study were compared to gene expression datasets related to amphibian regeneration published previously. Datasets included gene expression profiles from DNA microarray analysis of newt brain, spinal cord, hindlimbs, dorsal iris, heart, forelimbs and tail regeneration, microarray and RNA-seq analysis from axolotl limb regeneration, and LC-MS/MS from newt heart and axolotl limb regeneration. Newts and axolotls are presented with black color. Respective regenerating organs are colored white on the animals. The central grey column depicts the collection of all the gene expression data from the different regenerating tissues located at the periphery. The node and the three arrows represent the result of the data comparison. Boxes highlight the three major events of the common canonical regeneration program that was identified.

\section{Sample collection for LC-MS/MS}

Newts were anesthetized and whole eye balls were removed and placed in calcium- and magnesium-free (CMF) Hank's solution. Using scissors, eye balls were dissected and iris rings were isolated. Using a scalpel, dorsal and ventral $135^{\circ}$ sectors were extracted and kept frozen at $-70^{\circ} \mathrm{C}$ until use.
Sample collection for qPCR, RNA extraction, reverse transcriptase reaction, $\mathrm{QPCR}$ reactions, and enrichment analysis

All procedures were performed as described previously [6]. For primers and quantitative real-time polymerase chain reaction (qPCR) settings see Additional file 4. Student's $t$-test 
Table 7 Genes up-regulated during newt lens and axolotl limb regeneration

\begin{tabular}{|c|c|c|c|c|c|c|c|}
\hline$\overline{\mathrm{ABCA} 1^{1}}$ & $C 3^{3}$ & $\mathrm{EEF1E1}{ }^{2}$ & $\mathrm{HMOX} 1^{3}$ & $\mathrm{LSP}^{3}$ & $\mathrm{NCF}^{1}$ & $\mathrm{ROBO}^{4}$ & $\mathrm{TGFB1}^{2}$ \\
\hline$A B R^{2}$ & $\mathrm{CASP}^{3}$ & EMILIN $1^{4}$ & $\mathrm{HSPA}^{3}$ & $\mathrm{MARCO}^{3}$ & $\mathrm{OPTC}^{4}$ & SACS $^{3}$ & $\mathrm{TGM}^{2}$ \\
\hline $\mathrm{ACSBG}^{1}$ & $\mathrm{CFB}^{3}$ & $E R O 1 L^{3}$ & $\mathrm{HSPA}^{3}$ & $M C M 4^{5}$ & PAK2 ${ }^{5}$ & SAMD9L $^{5}$ & $\mathrm{TGM}^{2}$ \\
\hline ACSL4 ${ }^{1}$ & $\mathrm{CHIT} 1^{3}$ & $\mathrm{ETF}^{2}$ & $\mathrm{IDE}^{2}$ & $M C M 5^{5}$ & $P G D^{1}$ & SERPINB10 ${ }^{2}$ & $\mathrm{TGM}^{2}$ \\
\hline $\mathrm{AlF}^{3}$ & $\mathrm{CLPTM}^{3}$ & $\mathrm{~F} 13 \mathrm{~A} 1^{3}$ & $|F| H 1^{3}$ & $M C M 6^{5}$ & $\mathrm{PLEC}^{4}$ & $\mathrm{SLC} 30 \mathrm{~A} 1^{1}$ & $\mathrm{TLR}^{3}$ \\
\hline $\mathrm{ALOX5}^{1}$ & $\mathrm{CPT}_{1} \mathrm{~A}^{1}$ & FBLN $1^{4}$ & $\mathrm{ITGAD}^{4}$ & $\mathrm{MCM}^{5}$ & $\mathrm{PPID}^{3}$ & SOAT1 $^{1}$ & TMEM $43^{6}$ \\
\hline$A Q R^{2}$ & CSE1L $^{5}$ & $\mathrm{FBP}^{1}{ }^{1}$ & KIAA $1967^{5}$ & MOV10 2 & PSEN $1^{2}$ & TARS $^{2}$ & TNPO3 $^{2}$ \\
\hline $\mathrm{ASTL}^{4}$ & CUL1 ${ }^{5}$ & 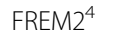 & LAMA3 & $\mathrm{MPO}^{3}$ & PTCD3 $^{2}$ & $\mathrm{TCN}^{1}{ }^{1}$ & VAMP8 ${ }^{2}$ \\
\hline $\mathrm{BCL} 2 \mathrm{~L} 1^{5}$ & $\mathrm{CYBA}^{1}$ & GIMAP7 $^{2}$ & $\mathrm{LGALS9}^{3}$ & $\mathrm{MYO}^{6} \mathrm{~F}^{6}$ & PTPRC $^{5}$ & TEX $2^{1}$ & $\mathrm{VCAN}^{4}$ \\
\hline$B C S 1 L^{1}$ & $\mathrm{CYBB}^{1}$ & $\mathrm{HK} 2^{1}$ & LMNA $^{4}$ & $\mathrm{NCCRP}^{5}$ & RAl14 $4^{6}$ & TFRC $^{1}$ & VSIG $4^{3}$ \\
\hline $\mathrm{C} 1 \mathrm{orf} 85^{2}$ & DNAJC5 ${ }^{1}$ & & & & & & \\
\hline
\end{tabular}

Gene function related to: metabolic process and transporters ${ }^{1}$, gene expression and protein homeostasis ${ }^{2}$, response to stress, host defense, immune response and reactive oxygen species ${ }^{3}$, migration, adhesion and extracellular matrix ${ }^{4}$, cell cycle, cell proliferation and DNA replication ${ }^{5}$, cytoskeleton, cell shape, and organelle shape ${ }^{6}$.

for independent samples was used to determine statistical significance for $\mathrm{qPCR}$ expression data. Equal variances were determined with Levene's test. Groups for enrichment analysis were selected as follows: For in vivo proteome analysis, protein expression was detected at $0 \mathrm{dpl}$ and at least for one of the 4- and 8-dpl samples. Only differences more than twofold were used for further bioinformatical analysis. Annotation was assigned to newt proteins using BLAST2GO with e-value less than 1E-10. GO mapping and annotation was performed with default settings. GO enrichment analysis was calculated using Fisher's exact test corrected for multiple selections which is a built-in feature of BLAST2GO $[53,54]$. GO terms were considered enriched when $\mathrm{FDR}<0.05$.

\section{Network analysis}

Network analysis was performed using VisANT [29]. For construction of the dorsal regeneration network, only proteins with more than twofold change during regeneration (4 and/or $8 \mathrm{dpl}$ ) compared to the intact control and more than twofold change compared to the equivalent timepoints in the ventral iris samples were included. The selected proteins were used as input for the program. Human gene names and the human interactome were used for this analysis. Only proteins that had at least one interaction with a different protein of the group were displayed. The same procedure was used for the construction of the ventral regeneration network.

\section{Newt IPE cell culture}

Newt dorsal and ventral IPE cell culture was performed as described previously with minor modifications [45]. Dorsal and ventral IPE cells were plated separately in DMEM on collagen I coated plates (Becton Dickinson, Franklin Lakes, NJ). Cells were incubated at $27^{\circ} \mathrm{C}$ with $2 \% \mathrm{CO}_{2}$. The medium was changed every other day till day 21. On day 21, dispase (Gibco, Life technologies,
Grand Island, NY) was added to the medium with a final concentration of $5 \%(v / v)$ and incubated overnight at $27^{\circ} \mathrm{C}$ with $2 \% \mathrm{CO}_{2}$. The collected cells were washed thrice with CMF Hank's solution and frozen with liquid nitrogen until use.

\section{LC-MS/MS procedures}

The iris tissue and cultured cells were isolated as described above. Proteins were isolated as described in [55] and processed for mass spectrometry (reversephase nano-LC-MS/MS, Thermo Velos and Q Exactive, Thermo Scientific, Waltham, MA) measurements. In brief, proteins were isolated by homogenizing tissue/ cells in a buffer containing $1 \%$ Nonidet P- $40,0.1 \%$ sodium deoxycholate, $150 \mathrm{~mm} \mathrm{NaCl}, 1 \mathrm{~mm}$ EDTA, and 50 $\mathrm{mm}$ Tris, $\mathrm{pH} 7.5$ and protease inhibitor mixture (Roche, San Francisco, CA). Next, proteins were separated by 1D SDS-PAGE and stained by Coomassie Blue. The gel was cut into eight slices per lane (each timepoint in vivo, dorsal and ventral in vitro). Gel slices were washed by $100 \mu \mathrm{L} 50 \mathrm{mM}$ ammonium bicarbonate (ABC)/50\% ethanol (EtOH) for $20 \mathrm{~min}$ at RT and dehydrated by incubating for $10 \mathrm{~min}$ in $100 \mu \mathrm{L}$ absolute EtOH. Protein reduction was performed by incubating the gel pieces in $100 \mu \mathrm{L} 10 \mathrm{mM}$ DTT (in $50 \mathrm{mM} \mathrm{ABC}$ ) for $45 \mathrm{~min}$ at $56^{\circ} \mathrm{C}$. Alkylation was done by incubating the gel pieces in $100 \mu \mathrm{L} 55 \mathrm{mM}$ iodacetamide for 30 min at RT in darkness. After a final washing step, gel pieces were dried and proteins were in-gel digested using trypsin overnight. For desalting, peptides were loaded onto STAGE-tips and eluted with $80 \%$ acetonitril for mass spectrometry (MS) analysis [56,57]. Reversedphase nano-LC-MS/MS was performed by using an Easy nanoflow HPLC system (Thermo Fisher Scientific, Odense Denmark; binary buffer system of A $(0.1 \%(v / v)$ formic acid in $\mathrm{H} 20)$ and B $(0.1 \%(v / v)$ formic acid in $80 \%$ acetonitrile); $50-\mathrm{cm}$ column $(75-\mu \mathrm{m} \mathrm{ID})$ packed in- 
house with $1.9-\mu \mathrm{m}$ diameter $\mathrm{C} 18$ resin). The HPLC is coupled to Q Exactive mass spectrometer (Thermo Fisher Scientific, Bremen, Germany) with an electrospray ionization source (Thermo Fisher Scientific, Bremen, Germany). MS spectra were acquired at a resolution of $70,000(200 \mathrm{~m} / \mathrm{z})$ in a mass range of $350-1,650 \mathrm{~m} / \mathrm{z}$ and the top 10 most intense ions were selected for fragmentation. To identify mass-spectrometry-derived spectra, a de-novo-assembled transcriptome [7] was utilized by translating it into six reading frames generating an Andromeda search engine [58] compatible database. Only reading frames greater than $50 \mathrm{AA}$ were used. Subsequent protein identification and label-free quantification was performed using MaxQuant software (Version 1.2.0.18) [59]. The maximum false discovery rate was set below $1 \%$ for peptide and protein identifications using the DECOY target database approach. Minimum peptide length was set to $7 \mathrm{AA}$ and two peptides per protein group (at least one unique peptide). Carbamidomethyl at cysteine residues was set as a fixed modification. Oxidation at methionine and acetylation at the $\mathrm{N}$-terminus were defined as variable modifications. Label-free quantification was based on at least two ratio counts. In vivo and in vitro LC-MS/MS data can be found in Additional file 2.

\section{Comparisons with other datasets}

Microarray, RNA sequencing, and LC-MS/MS data were extracted from the following papers: newt heart [50], forelimb, hindlimb, spinal cord, tail, brain, heart, tail [51], lens (dorsal iris) [8], and axolotl limb regeneration $[48,49,52]$. Genes were selected based on two expression criteria: expressed more than twofold in any of the regeneration timepoints compared to the control and not expressed more than twofold in the control compared to any of the regeneration timepoints. $\mathrm{Hu}$ man gene names were assigned to the extracted genes from all the datasets based on the annotation provided in the corresponding papers. Ambiguous annotations were discarded. The extracted genes can be found in Additional file 3. Comparisons, annotation assignments, and data mining were performed using custom Perl scripts.

\section{Comparison between in vitro LC-MS/MS and in vivo LC-MS/MS data}

In vitro LC-MS/MS data and in vivo LC-MS/MS data were normalized together for better correlation of expression levels. Pearson correlation was performed between dorsal IPE cell protein expression and the different timepoints of in vivo dorsal iris. Similar comparisons were performed with ventral samples. Tests were performed using Microsoft Office Excel spreadsheets.

\section{Additional files}

Additional file 1: Gene ontology enrichment analysis. Enrichment analysis using Fisher's exact test for genes up-regulated during in vivo regeneration versus control and in vitro ventral versus dorsal IPE cells.

Additional file 2: Protein expression data. Protein expression data from LC-MS/MS for 0, 4, and $8 \mathrm{dpl}$ dorsal and ventral iris, dorsal and ventral IPE in vitro cultured cells, and genes up-regulated at least twofold in dorsal or ventral IPE cells.

Additional file 3: Gene pools for common regeneration program analysis. Genes from previous high-throughput amphibian studies, which were up-regulated during different timepoints of regenerating versus control.

Additional file 4: Primer sequences and qPCR/PCR settings. All primers and $\mathrm{qPCR} / \mathrm{PCR}$ settings that were used for this study.

\section{Competing interests}

The authors declare that they have no competing interests

\section{Authors' contributions}

PAT and TB conceived the idea, designed the experiments, and wrote the manuscript. KS, RB, and ML performed experiments, analyzed data, and wrote the manuscript. MK and JB performed experiments. All authors read and approved the final manuscript.

\section{Acknowledgements}

This study is supported by NIH grant EY10450 to PAT. KS is supported in part by the University of Dayton Office of Graduate Academic Affairs through the Graduate Student Summer Fellowship Program.

\section{Author details}

'Department of Biology and Center for Tissue Regeneration and Engineering at Dayton, University of Dayton, 300 College Park, Dayton, OH 45469, USA.

${ }^{2}$ Department of Cardiac Development and Remodeling, Max-Planck-Institute for Heart and Lung Research, Ludwigstrasse 43, 61231 Bad Nauheim, Germany.

Received: 3 November 2014 Accepted: 17 November 2014

Published online: 11 December 2014

\section{References}

1. Baddour JA, Sousounis K, Tsonis PA: Organ repair and regeneration: an overview. Birth Defects Res C Embryo Today 2012, 96:1-29.

2. Barbosa-Sabanero K, Hoffmann A, Judge C, Lightcap N, Tsonis PA, Del Rio-Tsonis K: Lens and retina regeneration: new perspectives from model organisms. Biochem J 2012, 447:321-334.

3. Eguchi G, Shingai R: Cellular analysis on localization of lens forming potency in the newt iris epithelium. Dev Growth Differ 1971, 13:337-349.

4. Wolff G: Entwickelungsphysiologische studien. I. Die regeneration der urodelenlinse. Arch EntwMech Org 1895, 1:380-390.

5. Hoffmann A, Nakamura K, Tsonis PA: Intrinsic lens forming potential of mouse lens epithelial versus newt iris pigment epithelial cells in threedimensional culture. Tissue Eng Part C Methods 2014, 20:91-103.

6. Sousounis K, Looso M, Maki N, Ivester CJ, Braun T, Tsonis PA: Transcriptome analysis of newt lens regeneration reveals distinct gradients in gene expression patterns. PLoS One 2013, 8:e61445.

7. Looso M, Preussner J, Sousounis K, Bruckskotten M, Michel CS, Lignelli E, Reinhardt R, Hoeffner S, Krueger M, Tsonis PA, Borchardt T, Braun T: A de novo assembly of the newt transcriptome combined with proteomic validation identifies new protein families expressed during tissue regeneration. Genome Biol 2013, 14:R16.

8. Sousounis K, Michel CS, Bruckskotten M, Maki N, Borchardt T, Braun T, Looso $\mathrm{M}$, Tsonis PA: A microarray analysis of gene expression patterns during early phases of newt lens regeneration. Mol Vis 2013, 19:135-145.

9. Frye BC, Halfter S, Djudjaj S, Muehlenberg P, Weber S, Raffetseder U, En-Nia A, Knott H, Baron JM, Dooley S, Bernhagen J, Mertens PR: Y-box protein-1 is actively secreted through a non-classical pathway and acts as an extracellular mitogen. EMBO Rep 2009, 10:783-789. 
10. Hsieh HC, Chen YT, Li JM, Chou TY, Chang MF, Huang SC, Tseng TL, Liu CC, Chen SF: Protein profilings in mouse liver regeneration after partial hepatectomy using iTRAQ technology. J Proteome Res 2009, 8:1004-1013.

11. Duguez S, Bihan MC, Gouttefangeas D, Feasson L, Freyssenet D: Myogenic and nonmyogenic cells differentially express proteinases, $\mathrm{Hsc} / \mathrm{Hsp} 70$, and BAG-1 during skeletal muscle regeneration. Am J Physiol Endocrinol Metab 2003, 285:E206-E215.

12. Tawk M, Joulie C, Vriz S: Zebrafish Hsp40 and Hsc70 genes are both induced during caudal fin regeneration. Mech Dev 2000, 99:183-186.

13. Mitra P, Vaughan PS, Stein JL, Stein GS, van Wijnen AJ: Purification and functional analysis of a novel leucine-zipper/nucleotide-fold protein, BZAP45, stimulating cell cycle regulated histone $\mathrm{H} 4$ gene transcription. Biochemistry 2001, 40:10693-10699.

14. Braun MC, Kelly CN, Prada AE, Mishra J, Chand D, Devarajan P, Zahedi K: Human PRMT5 expression is enhanced during in vitro tubule formation and after in vivo ischemic injury in renal epithelial cells. Am J Nephrol 2004, 24:250-257.

15. Rouhana L, Vieira AP, Roberts-Galbraith RH, Newmark PA: PRMT5 and the role of symmetrical dimethylarginine in chromatoid bodies of planarian stem cells. Development 2012, 139:1083-1094.

16. Morikawa K, Oseko F, Morikawa S: The role of CD45 in the activation, proliferation and differentiation of human B lymphocytes. Int I Hematol 1991, 54:495-504.

17. Shivtiel S, Lapid K, Kalchenko V, Avigdor A, Goichberg P, Kalinkovich A, Nagler A, Kollet O, Lapidot T: CD45 regulates homing and engraftment of immature normal and leukemic human cells in transplanted immunodeficient mice. Exp Hematol 2011, 39:1161-1170. e1161.

18. Hu X, Addlagatta A, Lu J, Matthews BW, Liu JO: Elucidation of the function of type 1 human methionine aminopeptidase during cell cycle progression. Proc Natl Acad Sci U S A 2006, 103:18148-18153.

19. Li Y, Zhang P, Wang C, Han C, Meng J, Liu X, Xu S, Li N, Wang Q, Shi X, Cao $X$ : Immune responsive gene 1 (IRG1) promotes endotoxin tolerance by increasing A20 expression in macrophages through reactive oxygen species. J Biol Chem 2013, 288:16225-16234.

20. Przygodzka P, Ramstedt B, Tengel T, Larsson G, Wilczynska M: Bomapin is a redox-sensitive nuclear serpin that affects responsiveness of myeloid progenitor cells to growth environment. BMC Cell Biol 2010, 11:30.

21. Ueno S, Campbell J, Fausto N: Reactive oxygen species derived from NADPH oxidase system is not essential for liver regeneration after partial hepatectomy. J Surg Res 2006, 136:260-265.

22. Lyoumi S, Puy H, Tamion F, Scotte M, Daveau M, Nordmann Y, Lebreton JP, Deybach JC: Nitric oxide synthase inhibition and the induction of cytochrome P-450 affect heme oxygenase-1 messenger RNA expression after partial hepatectomy and acute inflammation in rats. Crit Care Med 1998, 26:1683-1689.

23. Nada SE, Tulsulkar J, Shah ZA: Heme oxygenase 1-mediated neurogenesis is enhanced by Ginkgo biloba (EGb 761(R)) after permanent ischemic stroke in mice. Mol Neurobiol 2013, 49:945-956.

24. Wagener FA, van Beurden HE, von den Hoff JW, Adema GJ, Figdor CG: The heme-heme oxygenase system: a molecular switch in wound healing. Blood 2003, 102:521-528.

25. Love NR, Chen Y, Ishibashi S, Kritsiligkou P, Lea R, Koh Y, Gallop JL, Dorey K Amaya $E$ : Amputation-induced reactive oxygen species are required for successful Xenopus tadpole tail regeneration. Nat Cell Biol 2013, 15:222-228.

26. Tyczewska M, Rucinski M, Ziolkowska A, Trejter M, Szyszka M, Malendowicz LK: Expression of selected genes involved in steroidogenesis in the course of enucleation-induced rat adrenal regeneration. Int J Mol Med 2014, 33:613-623.

27. Mace KA, Pearson JC, McGinnis W: An epidermal barrier wound repair pathway in Drosophila is mediated by grainy head. Science 2005, 308:381-385.

28. Wang J, Karra R, Dickson AL, Poss KD: Fibronectin is deposited by injuryactivated epicardial cells and is necessary for zebrafish heart regeneration. Dev Biol 2013, 382:427-435.

29. Hu Z, Snitkin ES, DeLisi C: VisANT: an integrative framework for networks in systems biology. Brief Bioinform 2008, 9:317-325.

30. Worapamorn W, Xiao Y, Li H, Young WG, Bartold PM: Differential expression and distribution of syndecan-1 and -2 in periodontal wound healing of the rat. J Periodontal Res 2002, 37:293-299.

31. Watanabe M, Kondo S, Mizuno K, Yano W, Nakao H, Hattori Y, Kimura K, Nishida T: Promotion of corneal epithelial wound healing in vitro and in vivo by annexin A5. Invest Ophthalmol Vis Sci 2006, 47:1862-1868.
32. Calve S, Odelberg SJ, Simon HG: A transitional extracellular matrix instructs cell behavior during muscle regeneration. Dev Biol 2010, 344:259-271.

33. Gilquin B, Cannon BR, Hubstenberger A, Moulouel B, Falk E, Merle N, Assard N, Kieffer S, Rousseau D, Wilder PT, Weber DJ, Baudier J: The calcium-dependent interaction between $\mathrm{S} 100 \mathrm{~B}$ and the mitochondrial AAA ATPase ATAD3A and the role of this complex in the cytoplasmic processing of ATAD3A. Mol Cell Biol 2010, 30:2724-2736.

34. Sadvakassova G, Dobocan MC, Difalco MR, Congote LF: Regulator of differentiation 1 (ROD1) binds to the amphipathic C-terminal peptide of thrombospondin-4 and is involved in its mitogenic activity. J Cell Physiol 2009, 220:672-679.

35. Tano K, Mizuno R, Okada T, Rakwal R, Shibato J, Masuo Y, ljiri K, Akimitsu N: MALAT-1 enhances cell motility of lung adenocarcinoma cells by influencing the expression of motility-related genes. FEBS Lett 2010, 584:4575-4580.

36. Daub H, Olsen JV, Bairlein M, Gnad F, Oppermann FS, Korner R, Greff Z, Keri G, Stemmann O, Mann M: Kinase-selective enrichment enables quantitative phosphoproteomics of the kinome across the cell cycle. Mol Cell 2008, 31:438-448.

37. Querido E, Blanchette P, Yan Q, Kamura T, Morrison M, Boivin D, Kaelin WG, Conaway RC, Conaway JW, Branton PE: Degradation of p53 by adenovirus E4orf6 and E1B55K proteins occurs via a novel mechanism involving a Cullin-containing complex. Genes Dev 2001, 15:3104-3117.

38. Mammen AL, Casciola-Rosen LA, Hall JC, Christopher-Stine L, Corse AM, Rosen A: Expression of the dermatomyositis autoantigen Mi-2 in regenerating muscle. Arthritis Rheum 2009, 60:3784-3793.

39. Boland $\mathrm{K}$, Flanagan $\mathrm{L}$, Prehn $\mathrm{JH}$ : Paracrine control of tissue regeneration and cell proliferation by Caspase-3. Cell Death Dis 2013, 4:e725.

40. Pechter PM, Gil J, Valdes J, Tomic-Canic M, Pastar I, Stojadinovic O, Kirsner RS, Davis SC: Keratin dressings speed epithelialization of deep partial-thickness wounds. Wound Repair Regen 2012, 20:236-242.

41. Fan X, Molotkov A, Manabe S, Donmoyer CM, Deltour L, Foglio MH Cuenca AE, Blaner WS, Lipton SA, Duester G: Targeted disruption of Aldh1a1 (Raldh1) provides evidence for a complex mechanism of retinoic acid synthesis in the developing retina. Mol Cell Biol 2003, 23:4637-4648

42. Triplett JW, Feldheim DA: Eph and ephrin signaling in the formation of topographic maps. Semin Cell Dev Biol 2012, 23:7-15.

43. Maloyan A, Osinska H, Lammerding J, Lee RT, Cingolani OH, Kass DA, Lorenz $\mathrm{JN}$, Robbins J: Biochemical and mechanical dysfunction in a mouse model of desmin-related myopathy. Circ Res 2009, 104:1021-1028.

44. Dunn RT 2nd, Kolaja KL, Klaassen CD: Effect of partial hepatectomy on the expression of seven rat sulphotransferase mRNAs. Xenobiotica 1999, 29:583-593

45. Bhavsar RB, Nakamura K, Tsonis PA: A system for culturing iris pigment epithelial cells to study lens regeneration in newt. J Vis Exp 2011, 52:e2713.

46. Tsonis PA, Jang W, Del Rio-Tsonis K, Eguchi G: A unique aged human retinal pigmented epithelial cell line useful for studying lens differentiation in vitro. Int J Dev Biol 2001, 45:753-758.

47. Tsonis PA, Trombley MT, Rowland T, Chandraratna RA, del Rio-Tsonis K: Role of retinoic acid in lens regeneration. Dev Dyn 2000, 219:588-593.

48. Campbell $L$, Suarez-Castillo EC, Ortiz-Zuazaga H, Knapp D, Tanaka EM, Crews CM: Gene expression profile of the regeneration epithelium during axolotl limb regeneration. Dev Dyn 2011, 240:1826-1840.

49. Stewart R, Rascon CA, Tian S, Nie J, Barry C, Chu LF, Ardalani H, Wagner RJ, Probasco MD, Bolin JM, Leng N, Sengupta S, Volkmer M, Habermann B, Tanaka EM, Thomson JA, Dewey CN: Comparative RNA-seq analysis in the unsequenced axolotl: the oncogene burst highlights early gene expression in the blastema. PLoS Comput Biol 2013, 9:e1002936.

50. Looso M, Michel CS, Konzer A, Bruckskotten M, Borchardt T, Kruger M, Braun $\mathrm{T}$ : Spiked-in pulsed in vivo labeling identifies a new member of the CCN family in regenerating newt hearts. J Proteome Res 2012, 11:4693-4704.

51. Mercer SE, Cheng CH, Atkinson DL, Krcmery J, Guzman CE, Kent DT, Zukor K, Marx KA, Odelberg SJ, Simon HG: Multi-tissue microarray analysis identifies a molecular signature of regeneration. PLoS One 2012, 7:e52375.

52. Rao N, Jhamb D, Milner DJ, Li B, Song F, Wang M, Voss SR, Palakal M, King MW, Saranjami B, Nye HL, Cameron JA, Stocum DL: Proteomic analysis of blastema formation in regenerating axolotl limbs. BMC Biol 2009, 7:83.

53. Conesa A, Gotz S, Garcia-Gomez JM, Terol J, Talon M, Robles M: Blast2GO: a universal tool for annotation, visualization and analysis in functional genomics research. Bioinformatics 2005, 21:3674-3676. 
54. Myhre S, Tveit H, Mollestad T, Laegreid A: Additional gene ontology structure for improved biological reasoning. Bioinformatics 2006, 22:2020-2027.

55. Looso M, Borchardt T, Kruger M, Braun T: Advanced identification of proteins in uncharacterized proteomes by pulsed in vivo stable isotope labeling-based mass spectrometry. Mol Cell Proteomics 2010, 9:1157-1166.

56. Shevchenko A, Wilm M, Vorm O, Mann M: Mass spectrometric sequencing of proteins silver-stained polyacrylamide gels. Anal Chem 1996, 68:850-858

57. Andersen JS, Lam YW, Leung AK, Ong SE, Lyon CE, Lamond Al, Mann M: Nucleolar proteome dynamics. Nature 2005, 433:77-83.

58. Cox J, Neuhauser N, Michalski A, Scheltema RA, Olsen JV, Mann M: Andromeda: a peptide search engine integrated into the MaxQuant environment. J Proteome Res 2011, 10:1794-1805.

59. Cox J, Mann M: MaxQuant enables high peptide identification rates, individualized p.p.b.-range mass accuracies and proteome-wide protein quantification. Nat Biotechnol 2008, 26:1367-1372.

doi:10.1186/s40246-014-0022-y

Cite this article as: Sousounis et al:: Molecular signatures that correlate with induction of lens regeneration in newts: lessons from proteomic analysis. Human Genomics 2014 8:22.

\section{Submit your next manuscript to BioMed Central and take full advantage of:}

- Convenient online submission

- Thorough peer review

- No space constraints or color figure charges

- Immediate publication on acceptance

- Inclusion in PubMed, CAS, Scopus and Google Scholar

- Research which is freely available for redistribution 